\title{
Palma Forrageira (Opuntia ficus indica Mill) em Substituição à Silagem de Sorgo (Sorghum bicolor (L.) Moench) na Alimentação de Vacas Leiteiras ${ }^{1}$
}

\author{
Walmir Lima Wanderley², Marcelo de Andrade Ferreira ${ }^{3,7}$, Dulciene Karla Bezerra de Andrade ${ }^{4}$, \\ Antônia Sherlânea Chaves Véras ${ }^{3}$, Iderval Farias ${ }^{5}$, Luís Evandro de Lima ${ }^{5}$, Argélia Maria de Araújo Dias ${ }^{6}$
}

RESUMO - O experimento foi conduzido com o objetivo de avaliar o desempenho de vacas da raça Holandesa em lactação, alimentadas com rações contendo diferentes níveis $(0,12,24$ e 36\%) de palma forrageira (Opuntia ficus indica Mill) em substituição à silagem de sorgo (Sorghum bicolor (L.) Moench). Foram utilizadas oito vacas distribuídas em dois quadrados latinos (4x4). Cada período experimental teve duração de 21 dias, sendo 14 destinados à adaptação dos animais às rações e sete para coleta. Os consumos de matéria seca (MS), em kg/dia, \% de PV e em relação ao peso metabólico $\left(\mathrm{g} / \mathrm{kg}^{0,75}\right)$, e matéria orgânica e carboidratos totais, expressos em $\mathrm{kg} / \mathrm{dia}$, não foram influenciados pela adição de palma na ração, apresentando valores médios de 20,18;3,41;167,80;18,86; e 14,85, respectivamente. O consumo de carboidratos não-fibrosos, em kg/dia, aumentou, e os de fibra em detergente neutro, em kg/dia e \% de PV, fibra em detergente ácido; proteína bruta e extrato etéreo, expressos em kg/dia, diminuíram linearmente com a inclusão de palma na ração. O consumo de sódio não foi influenciado pela adição de palma na ração, com valor médio de $29,45 \mathrm{~g} /$ dia. Os consumos de potássio e magnésio aumentaram e o de fósforo diminuiu linearmente com a adição de palma na ração. Não houve efeito da inclusão de palma sobre a produção de leite com e sem correção para 3,5\% de gordura, cujos valores médios foram de 25,01 e 26,97kg/dia, respectivamente. O teor de gordura do leite foi influenciado de forma quadrática, sendo o teor máximo estimado em $4,08 \%$, com $20,51 \%$ de palma na ração. A conversão alimentar aumentou linearmente com a inclusão de palma.

Palavras-chave: consumo, palma, produção de leite, silagem de sorgo

\section{Replacement of Forage Cactus (Opuntia ficus indica Mill) for Sorghum Silage (Sorghum bicolor (L.) Moench) in the Dairy Cows Feeding}

\begin{abstract}
The experiment was conducted to evaluate the performance of lactating Holstein cows fed diet with different replacement levels $(0,12,24$ and 36\%) of forage cactus (Opuntia ficus indica Mill) for sorghum silage (Sorghum bicolor (L.) Moench). Eight cows were assigned to a two $4 \times 4$ latin square design. Each experimental period lasted 21 days, 14 days for adaptation and 7 days for data collection. The intakes of dry matter (DM) in kg/day, \% of live weight (LW) and $\mathrm{g} / \mathrm{kg}^{0,75}$, organic matter and total carbohydrates in $\mathrm{kg} / \mathrm{day}$, were not affected by the forage cactus levels $(20.18,3.41,167.80,18.86$, and 14.85 , respectively). The nonfiber carbohydrates (kg/day) intake increased and the intakes of neutral detergent fiber ( $\mathrm{kg} /$ day and \% of LW), acid detergent fiber, crude protein and ether extract (kg/day) linearly decreased as the forage cactus levels increased. The sodium intake was not affected by the inclusion of forage cactus, with average value of $29.45 \mathrm{~g} / \mathrm{day}$. The potassium and magnesium intake increased and phosphorus intake linearly decreased. The milk production and fat corrected milk was not affected by the forage cactus levels ( 25.01 and $26.97 \mathrm{~kg} / \mathrm{day}$, respectively). There was a quadratic effect of levels of forage cactus on the milk fat concentration, with maximum milk fat of $4.08 \%$ with $20.51 \%$ of forage cactus. Feed:milk production ratio linearly decreased as the forage cactus levels increased.
\end{abstract}

Key Words: forage cactus, intake, milk production, sorghum silage

\section{Introdução}

De modo geral, o desempenho da pecuária na região semi-árida do nordeste do Brasil tem sido limitado pela baixa disponibilidade de forragens, principalmente nos períodos de prolongadas estiagens, além de manejo inadequado dos animais, má utilização dos recursos forrageiros existentes na região, pouco aproveitamento de forragens, em forma de silagem e feno, nos períodos das chuvas, e os altos custos das rações.

Segundo Pimentel et al. (1998), o sorgo tem ocupado extensas áreas nos últimos tempos, devido, principalmente, às suas características de tolerância ao déficit hídrico e capacidade de rebrota, em relação ao milho, o que permite maiores produções por área. Com maior produção de massa, o sorgo pode forne-

\footnotetext{
${ }_{1}^{1}$ Projeto parcialmente financiado pela FACEPE e realizado por intermédio do acordo IPA/UFRPE.

${ }^{2}$ Professor da Escola Agrotécnica Federal de Barreiros.

3Professor Adjunto do Depto de Zootecnia da UFRPE. E.mail: mcelo@yahoo.com

${ }^{4}$ Aluna do PPGZ da UFRPE.

${ }^{5}$ Pesquisador do IPA.

${ }^{6}$ Zootecnista.

${ }^{7}$ Pesquisador do CNPq.
} 
cer silagem mais barata e de valor nutritivo próximo à do milho. Embora o sorgo tenha estas características e seja uma alternativa importante para a região semi-árida, torna-se uma cultura de risco, devido às irregularidades das chuvas e longos períodos de estiagem que ocorrem nessa região.

Por outro lado, um grande potencial existente na região é a palma forrageira, que, por suas características morfo-fisiológicas, é uma planta adaptada às condições do semi-árido. Sua composição química é variável segundo a espécie, idade do artículo e época do ano (Santos, 1989), possuindo, em termos de nutrientes digestíveis totais (NDT), valor próximo aos de silagens de milho e sorgo (Farias et al., 1984). Os níveis de carboidratos solúveis são considerados altos, bem como os teores de cinza na matéria seca (MS), com destaque para o cálcio, 2,25 - 2,88\%; potássio, 1,5 - 2,45\%; e fósforo, 0,10 - 0,14\% (Santos et al., 1997). Contudo, baixos teores de MS, 10 a 14\%; fibra em detergente neutro (FDN), 26,8\%; e proteína bruta (PB), 4,0 a 5,3\%, precisam ser considerados no momento em que se utiliza essa forrageira como principal ingrediente nas dietas do gado leiteiro, em função de serem observados, nesta circunstância, baixo consumo de MS pelo animal com conseqüente perda de peso, baixo desempenho, distúrbios metabólicos, especialmente diarréias, e redução no teor de gordura do leite (Santana et al., 1972; Matter, 1986; Santos et al., 1990; Santos et al., 1997).

Aos problemas anteriormente observados soma-se a redução de ruminação, quando se utiliza palma isoladamente na alimentação dos ruminantes, principalmente com relação a vacas em lactação, havendo necessidade de fornecer adequada quantidade de fibra, proveniente de silagem, feno ou palhadas, com o propósito de aumentar o consumo de MS e prevenir desordens metabólicas (Oliveira, 1996).

A qualidade e quantidade da fibra interferem na atividade mastigatória, estimulando a secreção de saliva, a qual é rica em tampões que irão manter as condições normais de rúmen (Sudweeks et al., 1981; Allen, 1997). O NRC (1989) recomenda um mínimo de $21 \%$ de FDA e $28 \%$ de FDN na ração de vacas em lactação, com pelo menos $75 \%$ da FDN proveniente de volumoso.

As propriedades físicas das rações são afetadas diretamente pela proporção, pelo tipo de forragem e concentrado, pela proporção das fontes de fibra não forrageira, pelo tamanho das partículas e processamento dos ingredientes da ração(Wangsness \& Muller, 1981; Mertens, 1997; Armentano \& Pereira,
1997; Varga et al., 1998). O tamanho das partículas das forragens é uma característica importante, pois influencia a mastigação e ruminação (Mertens, 1997), com conseqüente alteração da relação acetato/propionato e do teor de gordura do leite (Allen \& Grant, 2000). A relação acetato/propionato está associada à redução do pH ruminal, que poderá interferir na produção de leite (Grant et al., 1990). De acordo com Poppi et al. (1985) e Cardoza (1985), citados por Mertens (1997), as partículas que passam direto por peneiras, com malhas de 1,2 $\mathrm{mm}$, passam rapidamente pelo rúmen e fornecem pouco ou nenhum estímulo para a mastigação.

Por outro lado, quando se fornece fibra proveniente de forragem de textura grosseira, promove-se maior tempo de retenção do alimento no rúmen, favorecendo sua melhor digestão (Grant, 1997) e resultando em maior relação acetato/propionato.

O fracionamento dos carboidratos é importante para se fazer um balanço adequado das rações, principalmente de vacas leiteiras, em função da peculiaridade na fermentação de cada fração e sua interferência no consumo, manutenção das condições normais do rúmen, produção e teor de gordura do leite (Sniffen et al., 1992). De acordo com Van Soest et al. (1991), o tipo e a quantidade dos carboidratos fibrosos e não-fibrosos afetam a fermentação e a eficiência microbiana.

A interação entre a fibra e os carboidratos nãofibrosos contidos na ração irá promover fermentação adequada, em função de a efetividade física da fibra provocar maior mastigação e ruminação, garantindo as condições normais de rúmen e produção e teor de gordura do leite satisfatórios (Slater et al., 2000). A fibra fisicamente efetiva é a fração do alimento que efetivamente irá estimular a atividade mastigatória e ruminatória, aumentando o fluxo salivar e contribuindo na manutenção das condições normais de rúmen. A atividade mastigatória, a proporção de acetato/ propionato ou a concentração de gordura no leite podem ser utilizadas para estimar a efetividade física das fontes de fibra em estimular a produção de saliva e conseqüente tamponamento do rúmen (Woodford et al., 1986; Allen, 1997; Armentano \& Pereira, 1997).

$\mathrm{Na}$ literatura consultada, há controvérsia quanto à produção, composição do leite e variação de peso, quando se utiliza a palma na alimentação de vacas Holandesas, puras de origem, puras por cruza ou mestiças, em lactação. Santana et al. (1972), comparando palma e silagem de milho, não observaram diferença na composição e na produção de leite. Por outro lado, os animais que receberam silagem ganha- 
ram $437 \mathrm{~g} / \mathrm{dia}$, enquanto os que receberam palma perderam $456 \mathrm{~g} /$ dia e aqueles que receberam $10 \mathrm{~kg}$ de silagem de milho e palma à vontade, perderam $230 \mathrm{~g}$.

Estudando a associação da palma forrageira com a silagem de sorgo, Lima et al. (1985) e Santos et al. (1998) não observaram diferença significativa na produção e na composição do leite e variação de peso dos animais. No entanto, Santos et al. (1992), avaliando cultivares de palma (miúda, gigante e redonda) em associação com silagem de milho doce, não constataram diferença significativa na produção média diária e teor de gordura do leite entre as três cultivares. Mesmo não havendo diferença na produção de leite, houve variação de peso, com perda nos tratamentos em que as cultivares gigante e redonda foram incluídas nas rações. Por outro lado, Santos et al. (1990), ao trabalharem com as mesmas cultivares, associadas à silagem de sorgo, não observaram diferença significativa na produção de leite e teor de gordura, porém, relataram perda de peso para as três cultivares.

Trabalhando com palma associada às silagens de milho e sorgo, Dias (1999) observou maior consumo de MS da silagem e da ração total pelos animais alimentados com silagem de milho, em relação àqueles que receberam silagem de sorgo; maior produção de leite para as vacas que consumiram silagem de milho em relação às que receberam silagem de sorgo em fase de grão leitoso, e não encontrou diferença significativa no teor de gordura do leite em todas as silagens avaliadas.

Mattos (2000), associando diferentes fontes de fibra na alimentação de vacas 5/8 Holandês:Zebu, não verificou diferença significativa na produção de leite com e sem correção do teor de gordura. Este mesmo autor observou consumo de FDN de até $1,12 \%$ PV e não verificou diarréia quando a palma participou em até $55,4 \%$ da ração total.

As condições do Agreste e do Sertão têm levado os criadores a utilizarem a palma como alimento básico para os seus rebanhos, pelo fato de sua utilização ser possível durante todo ano, principalmente na ocorrência de estiagens prolongadas. Tal importância vem justificar a procura em determinar a forma adequada de utilização da palma na alimentação de vacas leiteiras.

O objetivo deste trabalho foi avaliar o desempenho (consumo de nutrientes, produção de leite sem e com correção a 3,5\% de gordura, teor de gordura do leite e conversão alimentar) de vacas da raça Holandesa em lactação, alimentadas com rações contendo diferentes níveis de palma forrageira, em substituição à silagem de sorgo.

\section{Material e Métodos}

O experimento foi realizado na Estação Experimental de São Bento do Una - PE, pertencente à Empresa Pernambucana de Pesquisa Agropecuária - IPA, no período de novembro de 1999 a janeiro de 2000, com duração de 84 dias, divididos em quatro períodos de 21 dias, sendo 14 dias de adaptação às rações experimentais e sete dias para a coleta.

Foram utilizadas oito vacas da raça Holandesa, variedade preto e branco, com peso vivo médio e produção de leite média diária de 590 e $27 \mathrm{~kg}$, respectivamente. Os animais encontravam-se após o pico de lactação e nenhum deles havia sido inseminado, quando se iniciou o trabalho, o que assegurou, ao final do período experimental, um estádio de gestação não superior a cinco meses.

Os animais foram distribuídos aleatoriamente nos tratamentos contendo diferentes níveis de palma na ração $(0,12,24$ e $36 \%)$, em substituição à silagem de sorgo (Tabela 1).

$\mathrm{Na}$ Tabela 2 são apresentados os teores de matéria seca (MS), matéria orgânica (MO), proteína bruta (PB), fibra em detergente neutro (FDN), fibra em detergente ácido (FDA), carboidratos totais (CHO), carboidratos não-fibrosos ( $\mathrm{CNF}$ ), extrato etéreo $(\mathrm{EE})$, cálcio $(\mathrm{Ca})$, fósforo $(\mathrm{P})$, potássio $(\mathrm{K})$, magnésio $(\mathrm{Mg})$ e sódio $(\mathrm{Na})$ da palma, silagem de sorgo e do concentrado.

Os animais foram alojados, individualmente, em piquete com divisórias de madeira, cerca de arame e piso de terra com área coberta de $3 \mathrm{~m}^{2} \mathrm{e}$ área livre de, aproximadamente, $30 \mathrm{~m}^{2}$, com comedouro e bebedouro. A pesagem dos animais foi efetuada no início e no final de cada período experimental.

A ração foi formulada de acordo com as reco-

Tabela 1 - Composição percentual dos ingredientes nas rações (\% na MS)

Table 1 - Percentage of the ingredient in the diets (\% of DM)

\begin{tabular}{|c|c|c|c|c|}
\hline \multirow[t]{2}{*}{$\begin{array}{l}\text { Ingredientes }(\%) \\
\text { Ingredients }(\%)\end{array}$} & \multicolumn{4}{|c|}{$\begin{array}{c}\text { Níveis de palma } \% \\
\text { Level of forage cactus } \%\end{array}$} \\
\hline & 0 & 12 & 24 & 36 \\
\hline Palma & - & 12 & 24 & 36 \\
\hline Forage cactus & & & & \\
\hline $\begin{array}{l}\text { Silagem de sorgo } \\
\text { Sorghum silage }\end{array}$ & 57 & 45 & 33 & 21 \\
\hline $\begin{array}{l}\text { Concentrado } \\
\text { Concentrate }\end{array}$ & 43 & 43 & 43 & 43 \\
\hline
\end{tabular}


Tabela 2 - Teores de matéria seca (MS), matéria orgânica (MO), proteína bruta, fibra em detergente neutro (FDN), fibra em detergente ácido (FDA), carboidratos totais $(\mathrm{CHO})$, carboidratos nãofibrosos (CNF), extrato etéreo (EE), cálcio (Ca), fósforo $(\mathrm{P})$, potássio $(\mathrm{K})$, magnésio $(\mathrm{Mg})$ e sódio $(\mathrm{Na})$ da palma, silagem de sorgo e concentrado

Table 2 - Contents of dry matter (DM), organic matter (OM), crude protein (CP), neutral detergent fiber (NDF), acid detergent fiber (ADF), total carbohydrates (TC), non fiber carbohydrates (NFC), ether extract (EE), calcium (Ca) phosphorus $(P)$, potassium $(K)$, magnesium $(\mathrm{Mg})$ and sodium $(\mathrm{Na})$ of the forage cactus, sorghum silage and concentrate

\begin{tabular}{|c|c|c|c|}
\hline \multirow[t]{2}{*}{$\overline{\text { Itens }}$} & \multicolumn{3}{|c|}{$\begin{array}{l}\text { Ingredientes } \\
\text { Ingredients }\end{array}$} \\
\hline & $\begin{array}{c}\text { Palma } \\
\text { Forage } \\
\text { cactus }\end{array}$ & $\begin{array}{c}\text { Silagem } \\
\text { de sorgo } \\
\text { Sorghum silage }\end{array}$ & $\begin{array}{c}\text { Concentrado } \\
\text { Concentrate }\end{array}$ \\
\hline $\mathrm{MS}(D M), \%$ & 12,63 & 30,53 & 88,37 \\
\hline $\operatorname{MO}(O M), 1$ & 93,41 & 94,53 & 94,03 \\
\hline $\mathrm{PB}(C P), 1$ & 4,45 & 8,75 & 31,29 \\
\hline $\mathrm{FDN}(N D F),{ }^{1}$ & 26,17 & 65,12 & 9,6 \\
\hline FDA $(A D F), 1$ & 20,05 & 35,06 & 7,24 \\
\hline $\mathrm{CHO}(T C), 1,2$ & 87,96 & 83,82 & 61,05 \\
\hline $\mathrm{CNF}(N F C), 1,3$ & 61,79 & 18,70 & 51,45 \\
\hline $\mathrm{EE}^{1}$ & 0,84 & 1,65 & 1,70 \\
\hline $\mathrm{Ca}$ & 2,2 & 0,31 & 0,86 \\
\hline $\mathrm{P}^{1}$ & 0,12 & 0,21 & 0,75 \\
\hline $\mathrm{K}^{1}$ & 2,37 & 1,37 & 1,41 \\
\hline $\mathrm{Mg}^{1}$ & 0,85 & 0,36 & 0,19 \\
\hline $\mathrm{Na}^{1}$ & - & 0,026 & 0,32 \\
\hline
\end{tabular}

mendações do NRC (1989), para atender às exigências de produção de $30 \mathrm{~kg}$ de leite/vaca/dia com 3,5\% de gordura e constituída de palma (Opuntia ficus indica Mill), cultivar Gigante, picada à máquina no momento de cada refeição, associada à silagem de sorgo e ao concentrado, de acordo com os tratamentos experimentais (Tabela 1). O concentrado, confeccionado semanalmente, foi constituído de $50 \%$ de milho moído, $48 \%$ de farelo de soja moído, $1 \%$ de sal comum e $1 \%$ de complexo mineral comercial recomendado para vacas em lactação. A relação volumoso/concentrado foi de 57:43. A palma utilizada foi proveniente da própria Estação Experimental do IPA, colhida e ofertada diariamente aos animais. A silagem de sorgo, fornecida diariamente aos animais, foi armazenada em silos trincheira não-revestidos, próximos ao local do experimento.

A ração foi fornecida à vontade, em mistura completa, em duas refeições diárias, sendo $40 \%$ às $8 \mathrm{~h}$ e $60 \%$ às $17 \mathrm{~h}$, com água permanentemente à disposi- ção. Foi realizado ajuste diário dos alimentos ofertados para permitir sobras entre 5 e $10 \%$, garantindo o consumo voluntário da ração pelo animal e mantendo os níveis dos diferentes ingredientes nas rações. Diariamente, os animais foram transferidos nas horas mais quentes do dia para um local sombreado, onde permaneceram das $11 \mathrm{~h}$ às $15 \mathrm{~h} 30$, quando foram levados para o estábulo de ordenha, retornando aos piquetes às $17 \mathrm{~h}$.

Amostras dos alimentos fornecidos (palma, silagem e concentrado), bem como das sobras, foram coletadas por animal e por dia, sendo, em seguida, pré-secas e homogeneizadas para obtenção de amostra composta, em cada período experimental, para análises posteriores de MS, cinzas, PB, FDN, FDA e EE, segundo Silva (1990), e P, K, Mg e Na, conforme metodologia proposta por Bezerra Neto et al. (1994). Os teores de $\mathrm{CHO}$ e $\mathrm{CNF}$ foram determinados segundo as fórmulas: $\mathrm{CHO}=100-(\mathrm{PB}+\mathrm{EE}+\mathrm{CINZAS})$ e $\mathrm{CNF}=$ $100-(\mathrm{FDN}+\mathrm{PB}+\mathrm{EE}+\mathrm{CINZAS})$, preconizadas por Sniffen et al. (1992) e Mertens (1997), respectivamente. As análises bromatológicas foram realizadas nos Laboratórios de Nutrição Animal dos Departamentos de Zootecnia, Química Vegetal e Química do Solo da Universidade Federal Rural de Pernambuco.

A produção individual de leite foi registrada por ocasião da ordenha mecânica com balde ao pé, realizada às 6 e 16h. A gordura do leite foi determinada pelo método de Gerber (Behmer, 1965). Para o cálculo da produção de leite corrigida a 3,5\% de gordura (PLCG), foi utilizada a fórmula proposta por Sklan et al. (1992): PLCG $=(0,432+0,1625 \times$ \% Gordura do leite $) \times$ produção de leite em kg/dia, citada por Suárez Londoño et al. (1997).

O delineamento experimental foi o quadrado latino $(4 \times 4)$, sendo quatro animais, quatro períodos e quatro níveis de inclusão de palma forrageira na ração. Foram utilizados dois quadrados simultâneos, um com vacas de segunda e outro com vacas de terceira lactação. Houve perda de duas parcelas, as quais foram estimadas segundo metodologia proposta por Sampaio (1998). Os dados foram submetidos à análise de variância e regressão, utilizando-se o programa SAEG (Sistemas de Análises Estatísticas e Genéticas) da Universidade Federal de Viçosa (UFV, 1997).

\section{Resultados e Discussão}

Na Tabela 3 são apresentados os teores de matéria seca (MS), matéria orgânica (MO), proteína bruta (PB), fibra em detergente neutro (FDN), fibra em 
detergente ácido (FDA), carboidratos totais (CHO), carboidratos não-fibrosos (CNF), extrato etéreo (EE), fósforo $(\mathrm{P})$, potássio $(\mathrm{K})$, magnésio $(\mathrm{Mg})$ e sódio $(\mathrm{Na})$ das rações experimentais.

Como pode ser observado, o teor de matéria seca (MS) das rações variou de 48,95 a 55,40\%, estando próximo do limite máximo preconizado pelo NRC (1989), que é de 50\%, abaixo do qual o consumo seria limitado. A proteína bruta (PB) ficou acima dos $16 \%$ recomendados pelo NRC (1989) para as necessidades dos animais. Isto foi devido, principalmente, ao teor de PB da silagem (Tabela 2), que foi maior que o estimado quando da formulação das rações experimentais. O teor de fibra em detergente neutro (FDN) variou de 41,24 a $27,22 \%$ e o de fibra em detergente ácido (FDA), de 23,10 a 17,69\%. As recomendações mínimas do NRC (1989) são de 28 e $21 \%$ para FDN e FDA, respectivamente. Os níveis de CNF nas rações variaram de 33,06 a 48,49\%, sendo superiores aos recomendados pelo NRC (2001), de 32 a $43 \%$.

Os teores de cálcio, com exceção do nível zero de inclusão de palma, ficaram acima das recomenda-

Tabela 3 - Teores de matéria seca (MS), matéria orgânica (MO), proteína bruta (PB), fibra em detergente neutro (FDN), fibra em detergente ácido (FDA), carboidratos totais ( $\mathrm{CHO})$, carboidratos nãofibrosos (CNF), extrato etéreo (EE), cálcio $(\mathrm{Ca})$, fósforo $(P)$, potássio $(K)$, magnésio $M g)$ e sódio (Na) das rações

Table 3 - Contents of dry matter (DM), organic matter (OM), crude protein (CP), neutral detergent fiber (NDF), acid detergent fiber (ADF), total carbohydrates (TC), non fiber carbohydrates (NFC), ether extract (EE), calcium $(\mathrm{Ca})$, phosphorus $(\mathrm{P})$, potassium $(\mathrm{K})$, magnesium $(\mathrm{Mg})$ and sodium $(\mathrm{Na})$ of the diets

\begin{tabular}{lrrrr}
\hline Itens & \multicolumn{4}{c}{ Níveis de palma (\%) } \\
& \multicolumn{4}{c}{ Forage cactus levels (\%) } \\
\cline { 2 - 5 } & 55,40 & 53,25 & 51,10 & 48,95 \\
\hline MS $(D M), \%$ & 94,31 & 94,18 & 94,04 & 93,91 \\
MO $(O M), 1$ & 18,44 & 17,92 & 17,41 & 16,89 \\
PB $(C P), 1$ & 41,24 & 36,57 & 31,90 & 27,22 \\
FDN $(N D F), 1$ & 23,10 & 21,30 & 19,50 & 17,69 \\
FDA $(A F D), 1$ & 74,30 & 74,33 & 75,32 & 75,71 \\
CHO $(T C), 1,2$ & 33,06 & 37,76 & 43,42 & 48,49 \\
CNF $(N F C), 1,3$ & 1,67 & 1,57 & 1,47 & 1,38 \\
$\mathrm{EE}^{1}(E E)$ & 0,49 & 0,73 & 0,96 & 1,19 \\
$\mathrm{Ca}^{1}$ & 0,44 & 0,43 & 0,42 & 0,41 \\
$\mathrm{P}^{1}$ & 1,39 & 1,50 & 1,63 & 1,75 \\
$\mathrm{~K}^{1}$ & 0,29 & 0,34 & 0,40 & 0,46 \\
$\mathrm{Mg}^{1}$ & 0,15 & 0,15 & 0,14 & 0,14 \\
$\mathrm{Na}^{1}$ & & & &
\end{tabular}

$1 \%$ na MS (\% DM).

${ }^{2}$ Sniffen et al. (1992).

3 Mertens (1997). ções do NRC (1989). A relação cálcio/fósforo foi relativamente alta, variando de 1,11 a 2,9. Entretanto, vários trabalhos mostraram que esta relação entre $1: 1$ e 8:1 resultou em desempenhos semelhantes (Lucci, 1997; NRC, 1989).

O NRC (1989) recomenda, para os níveis de exigências dos animais deste experimento, com base na matéria seca, teores de fósforo $(\mathrm{P})$, potássio $(\mathrm{K})$, magnésio $(\mathrm{Mg})$ e sódio $(\mathrm{Na})$ nas rações de 0,28 a 0,$42 ; 0,9$ a 1,0; 0,20 a 0,25 ; e $0,18 \%$, respectivamente. Quando comparado a estes valores, observa-se, na Tabela 3, que o teor de fósforo (P) variou de 0,41 a $0,44 \%$, atendendo as exigências dos animais. Os teores de potássio $(\mathrm{K})$ e magnésio $(\mathrm{Mg})$ variaram de 1,39 a 1,75 e 0,29 a 0,46\%, respectivamente, sendo superiores às necessidades, e o teor de sódio variou de 0,14 a $0,15 \%$, ficando próximo do preconizado pelo referido sistema.

$\mathrm{Na}$ Tabela 4, são apresentados os resultados referentes ao consumo médio de matéria seca (CMS), matéria orgânica (CMO), carboidratos totais (CCHO), carboidratos não-fibrosos (CCNF), fibra em detergente neutro $(\mathrm{CFDN})$, fibra em detergente ácido (CFDA), proteína bruta (CPB) e extrato etéreo (CEE), bem como as equações de regressão (ER) e os coeficientes de determinação $\left(\mathrm{r}^{2}\right)$ e variação $(\mathrm{CV})$, em função dos níveis de palma.

Os consumos de MS (em kg/dia, \% de PV e unidade de tamanho metabólico $\mathrm{g} / \mathrm{kg}^{0,75}$ ) e de MO e $\mathrm{CHO}$, expressos em $\mathrm{kg} / \mathrm{dia}$, não foram influenciados $(\mathrm{P}>0,05)$ pela inclusão de palma na ração, apresentando valores médios de 20,18; 3,41; 167,8; 18,86; e 14,85 , respectivamente.

$\mathrm{O}$ consumo de MS, em \% de PV, independentemente do tratamento, ficou acima do sugerido pelo NRC (1989), que é de 3,2\% do PV, para vacas com produção diária e PV médio de 25 e 600 kg, respectivamente, sendo superior aos encontrados por Lima et al. (1985) e DIAS (1999), que foram de 2,74 e 1,96\% de PV, respectivamente.

Esta superioridade no consumo deve-se, provavelmente, ao nível de produção de leite mais alto; ao fornecimento do alimento na forma de ração completa, o que poderia ter proporcionado, ao longo do dia, melhor aporte de nutrientes, favorecendo e uniformizando a fermentação ruminal, principalmente na concentração de ácidos graxos voláteis; e ao fato de os animais terem recebido manejo diferenciado, pois, nas horas mais quentes do dia, foram levados a um local sombreado, proporcionando-lhes maior conforto. Além disso, os animais receberam $60 \%$ da ração 
diária após a ordenha da tarde, período com temperatura mais amena. Geralmente, em função do desconforto térmico, os animais reduzem a ingestão, com conseqüente diminuição na produção de leite (Damasceno et al., 1998; Pires et al., 2000).

$\mathrm{O}$ consumo de $\mathrm{CNF}$, em kg/dia, aumentou $(\mathrm{P}<0,05)$ e os de FDN, em kg/dia e \% de PV; FDA; PB e EE, expressos em $\mathrm{kg} /$ dia, diminuíram linearmente $(\mathrm{P}<0,05)$ com a inclusão de palma na ração. Isto, possivelmente, foi devido ao maior teor de $\mathrm{CNF}$ e às menores concentrações de PB, FDN, FDA e EE nas rações, com a inclusão da palma (Tabela 3 ). O consumo de FDN, no tratamento sem inclusão de palma (1,4\% do PV), está acima do valor sugerido por Mertens (1992) como limitante do consumo de MS, que é de $1,2+0,1 \%$ do PV para vacas em lactação, e próximo ao observado por Ruiz et al. (1995), ao trabalharem com diferentes níveis de FDN na ração.

$\mathrm{Na}$ Tabela 5, são apresentados os resultados relativos ao consumo médio de cálcio $(\mathrm{CCa})$, fósforo
(CP), potássio $(\mathrm{CK})$, magnésio $(\mathrm{CMg})$ e sódio $(\mathrm{CNa})$, bem como as equações de regressão (ER), os coeficientes de determinação $\left(\mathrm{r}^{2}\right)$ e variação $(\mathrm{CV})$ dos diferentes tratamentos experimentais, no quais se observa que os consumos de $\mathrm{Ca}, \mathrm{K}$ e $\mathrm{Mg}$ aumentaram linearmente $(\mathrm{P}<0,01)$ com inclusão da palma na ração. Isto pode ser parcialmente justificado pelo aumento da proporção de palma nas dietas, pois esta é rica nestes elementos (Tabela 2). O consumo de $\mathrm{P}$ diminuiu linearmente $(\mathrm{P}<0,05)$ e o de $\mathrm{Na}$ não foi influenciado $(\mathrm{P}>0,05)$ pela inclusão da palma na ração, com valor médio de 29,45 g/dia.

$\mathrm{Na}$ Tabela 6, são apresentados os resultados médios referentes à produção de leite (PL) e produção de leite corrigido a 3,5\% de gordura (PLCG), em $\mathrm{kg} / \mathrm{dia}$, teor de gordura do leite (TG), em \%, conversão alimentar (CA), $\mathrm{kg}$ de MS consumida/kg de leite produzido, bem como as equações de regressão (ER), coeficientes de determinação $\left(\mathrm{r}^{2} / \mathrm{R}^{2}\right)$ e variação $(\mathrm{CV})$,

Tabela 4 - Média, equações de regressão ajustadas (ER) e coeficientes de variação $(C V)$ e determinação $\left(r^{2}\right)$ para os consumos de matéria seca (CMS), matéria orgânica (CMO), carboidratos totais (CCHO), carboidratos não-fibrosos (CCNF), fibra em detergente neutro (CFDN), fibra em detergente ácido (CFDA), proteína bruta (CPB) e extrato etéreo (CEE), em função dos níveis de palma

Table 4 - Means, fitted regression equations (RE) and coefficients of variation (CV) and determination ( $\left.r^{2}\right)$ for the intakes of dry matter (IDM), organic matter (IOM), total carbohydrates (ITC), nonfiber carbohydrates (INFC), neutral detergent fiber (INDF), acid detergent fiber (IADF), crude protein (ICP) and ether extract (IEE), according to the forage cactus levels

\begin{tabular}{|c|c|c|c|c|c|c|c|}
\hline \multirow[t]{2}{*}{ Itens } & \multicolumn{4}{|c|}{$\begin{array}{c}\text { Níveis de palma }(\%) \\
\text { Forage cactus levels }(\%)\end{array}$} & \multirow[t]{2}{*}{$\begin{array}{l}\mathrm{ER} \\
\mathrm{RE}\end{array}$} & \multirow[t]{2}{*}{$\begin{array}{l}\mathrm{r}^{2} \\
(\%)\end{array}$} & \multirow[t]{2}{*}{$\begin{array}{l}\mathrm{CV} \\
(\%)\end{array}$} \\
\hline & 0 & 12 & 24 & 36 & & & \\
\hline $\begin{array}{l}\text { CMS ( } \mathrm{kg} / \mathrm{dia}) \\
I D M(\mathrm{~kg} / \text { day })\end{array}$ & 20,95 & 19,97 & 20,98 & 18,82 & $\hat{Y}=20,18$ & - & 9,1 \\
\hline $\begin{array}{l}\mathrm{CMS}(\% \mathrm{PV}) \\
I D M(\% L W)\end{array}$ & 3,59 & 3,35 & 3,54 & 3,18 & $\hat{\mathrm{Y}}=3,41$ & - & 8,7 \\
\hline $\begin{array}{l}\text { CMS }\left(\mathrm{g} / \mathrm{kg}^{0,75}\right) \\
I D M\left(g / \mathrm{kg}^{75}\right)\end{array}$ & 161,98 & 166,15 & 166,76 & 176,30 & $\hat{\mathrm{Y}}=167,80$ & - & 8,8 \\
\hline $\begin{array}{l}\mathrm{CMO}(\mathrm{kg} / \mathrm{dia}) \\
I O M(\mathrm{~kg} / \text { day })\end{array}$ & 19,69 & 18,32 & 19,72 & 17,69 & $\hat{\mathrm{Y}}=18,86$ & - & 10,7 \\
\hline $\begin{array}{l}\mathrm{CCHO}(\mathrm{kg} / \mathrm{dia}) \\
\text { ICTC (kg/day) }\end{array}$ & 15,39 & 14,27 & 15,59 & 14,14 & $\hat{\mathrm{Y}}=14,85$ & - & 11,9 \\
\hline $\begin{array}{l}\mathrm{CCNF}(\mathrm{kg} / \text { dia }) \\
I N F C(\mathrm{~kg} / \text { day })\end{array}$ & 7,13 & 7,54 & 9,25 & 9,39 & $\hat{\mathrm{Y}}=7,0577+0,0775 \mathrm{P}^{*}$ & 89,0 & 14,3 \\
\hline $\begin{array}{l}\mathrm{CFDN}(\mathrm{kg} / \mathrm{dia}) \\
I N D F(\mathrm{~kg} / \text { day })\end{array}$ & 8,25 & 6,73 & 6,34 & 4,80 & $\hat{\mathrm{Y}}=8,1444-0,08945 \mathrm{P}^{*}$ & 96,0 & 11,1 \\
\hline $\begin{array}{l}\text { CFDN }(\% \mathrm{PV}) \\
I N D F(\% L W)\end{array}$ & 1,40 & 1,12 & 1,05 & 0,81 & $\hat{\mathrm{Y}}=1,3751-0,01527 \mathrm{P}^{*}$ & 96,0 & 11,9 \\
\hline $\begin{array}{l}\text { CFDA (kg/dia) } \\
I A D F(\mathrm{~kg} / \text { day })\end{array}$ & 4,77 & 4,07 & 3,99 & 3,30 & $\hat{\mathrm{Y}}=4,7096-0,0375 \mathrm{P}^{*}$ & 93,0 & 9,8 \\
\hline $\begin{array}{l}\mathrm{CPB}(\mathrm{kg} / \mathrm{dia}) \\
I C P(\mathrm{~kg} / \text { day })\end{array}$ & 4,01 & 3,73 & 3,73 & 3,23 & $\hat{\mathrm{Y}}=4,0274-0,01959 \mathrm{P}^{*}$ & 87,0 & 7,7 \\
\hline $\begin{array}{l}\mathrm{CEE} \mathrm{kg/dia} \\
\text { IEE (kg/day) }\end{array}$ & 0,365 & 0,316 & 0,322 & 0,263 & $\hat{\mathrm{Y}}=0,36-0,00245 \mathrm{P}^{*}$ & 86,0 & 8,2 \\
\hline
\end{tabular}

$\mathrm{P}=$ Nível de palma na ração (Level of forage cactus).

* Significativo $(P<0,05)$ pelo teste $t\left({ }^{*}\right.$ Significant at $(P<.05)$, by $t$ test $)$. 
Palma Forrageira (Opuntia ficus indica Mill) em Substituição à Silagem de Sorgo (Sorghum bicolor (L.) Moench)...

Tabela 5 - Média, equações de regressão ajustadas (ER) e coeficientes de variação $(C V)$ e determinação $\left(r^{2}\right)$ para os consumos de cálcio $(\mathrm{CCa})$, fósforo $(\mathrm{CP})$, potássio $(\mathrm{CK})$, magnésio $(\mathrm{CMg})$ e sódio $(\mathrm{CNa})$ em função dos níveis de palma

Table 5 - Means, fitted regression equations (RE) and coefficients of variation (CV) and determination ( $\left.r^{2}\right)$ for the intakes of calcium (ICa), phosphorus (IP), potassium (IK), magnesium (IMg) and sodium (INa), according to the forage cactus levels

\begin{tabular}{|c|c|c|c|c|c|c|c|}
\hline \multirow[t]{2}{*}{ Itens } & \multicolumn{4}{|c|}{$\begin{array}{c}\text { Níveis de palma }(\%) \\
\text { Forage cactus levels }(\%)\end{array}$} & \multirow[t]{2}{*}{$\begin{array}{l}\mathrm{ER} \\
R E\end{array}$} & \multirow[t]{2}{*}{$\begin{array}{l}\mathrm{r}^{2} \\
(\%)\end{array}$} & \multirow[t]{2}{*}{$\begin{array}{l}\mathrm{CV} \\
(\%)\end{array}$} \\
\hline & 0 & 12 & 24 & 36 & & & \\
\hline $\begin{array}{l}\mathrm{Cca}(\mathrm{g} / \mathrm{dia}) \\
\mathrm{ICa}(\mathrm{g} / \mathrm{day})\end{array}$ & 106,72 & 138,78 & 189,70 & 207,10 & $\hat{\mathrm{Y}}=107,77+2,9338 \mathrm{P} * *$ & 97,0 & 15,12 \\
\hline $\begin{array}{l}\mathrm{CP}(\mathrm{g} / \mathrm{dia}) \\
I P(g / \text { day })\end{array}$ & 91,18 & 89,20 & 90,45 & 78,41 & $\hat{\mathrm{Y}}=92,8138-0,301458 \mathrm{P}^{*}$ & 64,0 & 10,79 \\
\hline $\begin{array}{l}\mathrm{CK}(\mathrm{g} / \mathrm{dia}) \\
I K(g / d a y)\end{array}$ & 277,10 & 287,66 & 338,82 & 323,32 & $\hat{\mathrm{Y}}=278,253+1,58198 \mathrm{P} * *$ & 71,0 & 11,37 \\
\hline $\begin{array}{l}\mathrm{CMg}(\mathrm{g} / \mathrm{dia}) \\
\operatorname{Img}(\mathrm{g} / \text { day })\end{array}$ & 60,46 & 68,53 & 84,90 & 86,62 & $\hat{\mathrm{Y}}=60,9037+0,790417 \mathrm{P} * *$ & 93,0 & 11,22 \\
\hline $\begin{array}{l}\mathrm{CNa}(\mathrm{g} / \mathrm{dia}) \\
I N a(g / d a y)\end{array}$ & 29,96 & 29,94 & 29,82 & 28,07 & $\hat{\mathrm{Y}}=29,45$ & - & 12,34 \\
\hline
\end{tabular}

$\mathrm{P}=\quad$ Nível de palma na ração (Forage cactus levels).

${ }^{*} \mathrm{e}^{* *}$ Significativo a $(P<0,05)$ e $(P<0,01)$, respectivamente, pelo teste $\mathrm{t}\left({ }^{*}\right.$ and ${ }^{* *}$ Significant at $[P<.05]$ and $[P<.01]$, respectively, by $t$ test $)$.

em função dos níveis de palma na ração. Pode-se observar que não houve efeito $(\mathrm{P}>0,05)$ dos níveis de palma na ração sobre a produção de leite sem e com correção a 3,5\% de gordura, em kg/vaca/dia. Contudo, estes resultados foram bem superiores aos observados por vários autores (Lima et al., 1985; Santos et al., 1990; Santos et al., 1998; Dias, 1999), que, trabalhando com vacas da raça Holandesa, associando palma forrageira à silagem de sorgo e/ou de milho, obtiveram, respectivamente, os seguintes resultados para produção de leite sem e com correção a $4 \%$, em $\mathrm{kg} / \mathrm{dia}: 14,70$ e 13,$86 ; 12,35$ e 10,$74 ; 12,74$ e 11,19 ; 14,02 e 12,97. Porém, vários aspectos devem ser salientados em relação a estas diferenças: nível de produção dos animais, transferência dos animais para local sombreado nas horas mais quentes do dia, nível de fibra nas rações bem próximo do recomendado, fornecimento de ração completa, entre outros.

Na Tabela 6, observa-se que o teor de gordura do leite foi influenciado de forma quadrática $(\mathrm{P}<0,05)$, sendo o teor máximo estimado em 4,08\% com 20,51\% de palma na ração. Estes resultados foram superiores aos encontrados por Lima et. al. (1985), Santos et al. (1990), Santos et al. (1998) e Dias (1999), que encontraram 3,$63 ; 3,14 ; 3,20$; e $3,53 \%$, respectivamente.

O fato de a palma possuir altos níveis de carboidratos solúveis (Santos et al., 1992; Santos et al., 1997) e pectina (Silva et al., 1997) pode explicar parcialmente o aumento do teor de gordura do leite, pois a pectina é um carboidrato que, ao se comparar às fontes tradicionais de amido, proporciona melhor padrão de fermentação ruminal, produção de ácidos galacturônicos, com poder tampão, não produzindo ácido láctico e nem reduzindo o pH (Van Soest et al., 1991, Howard, 1961, Strobel e Russel, 1986, citados por Hall et al., 1997; Belibasakis et al., 1995, citados por Assis et al., 2000). Por outro lado, a redução no teor de gordura do leite poderá ter sido em função de que, com o aumento da quantidade de palma, diminuiu o teor de FDN e aumentou o de CNF na ração. Como resultado, pode ter ocorrido diminuição na efetividade da fibra com conseqüente redução na mastigação, ruminação e produção de saliva, não garantindo as condições normais de rúmen para manter em níveis normais o teor de gordura do leite (Slater, 2000; Allen, 1997; Woodford et al., 1986).

Mattos (2000) não verificou alteração no teor de gordura de vacas mestiças, trabalhando com palma associada a diferentes volumosos e com níveis de FDN acima daquele recomendado pelo NRC (1989).

O teor máximo de gordura do leite estimado em função do teor de CNF na ração foi de $4,17 \%$, com $42,38 \%$ de CNF ( $\mathrm{Y}=-2,4749+0,3136 \mathrm{x}-0,0037 \mathrm{x}^{2}$, $\mathrm{R}^{2}=94,8 \%$ ). Este valor está muito próximo do limite máximo recomendado pelo NRC (2001), que foi de $43 \%$. Comportamento semelhante foi verificado por Valadares Filho et al. (2000), ao trabalharem com vacas em lactação utilizando fonte tradicional de amido, estimando máximo de teor de gordura do leite com 30,2\% de CNF na ração.

Vários trabalhos têm relatado distúrbios metabólicos, como diarréias, com o uso da palma forrageira, 
Tabela 6 - Médias, equações de regressão ajustadas (ER) e coeficientes de variação (CV) e determinação $\left(R^{2} / r^{2}\right)$ para produção de leite (PL) e produção de leite corrigida a 3,5\% de gordura (PLCG), teor de gordura do leite (TG), e conversão alimentar (CA), $\mathrm{kg}$ de matéria seca consumida/kg de leite produzido, em função dos níveis de palma

Table 6 - Means, fitted regression equations $(R E)$ and coefficients of variation $(C V)$ and determination $\left(R^{2} / r^{2}\right)$ for milk production $(M P)$ and fat corrected milk (FCM) 3,5\%, milk fat, feed:milk production ratio (feed:MP ratio), according to the forage cactus levels (\%)

\begin{tabular}{|c|c|c|c|c|c|c|c|}
\hline \multirow[t]{2}{*}{ Itens } & \multicolumn{4}{|c|}{$\begin{array}{c}\text { Níveis de palma }(\%) \\
\text { Forage cactus levels }(\%)\end{array}$} & \multirow[t]{2}{*}{$\begin{array}{l}\mathrm{ER} \\
R E\end{array}$} & \multirow[t]{2}{*}{$\begin{array}{c}\mathrm{r}^{2} / \mathrm{R}^{2} \\
(\%)\end{array}$} & \multirow[t]{2}{*}{$\begin{array}{l}\mathrm{CV} \\
(\%)\end{array}$} \\
\hline & 0 & 12 & 24 & 36 & & & \\
\hline $\begin{array}{l}\mathrm{PL}(\mathrm{kg} / \mathrm{dia}) \\
M P \text { (kgday) }\end{array}$ & 24,98 & 24,62 & 25,70 & 24,75 & $\hat{\mathrm{Y}}=25,01$ & - & 5,4 \\
\hline $\begin{array}{l}\text { PLCG (kg/dia) } \\
F C M(\mathrm{~kg} / \text { dav })\end{array}$ & 26,59 & 26,61 & 28,39 & 26,30 & $\hat{Y}=26,97$ & - & 4,9 \\
\hline TG $($ Fat $) \%$ & 3,81 & 3,99 & 4,11 & 3,91 & $\hat{\mathrm{Y}}=3,8047+0,02695 \mathrm{P}^{*}-0,000657 \mathrm{P}^{2 *}$ & 93,0 & 5,2 \\
\hline Feed:MPratio & 0,83 & 0,81 & 0,81 & 0,77 & $\hat{\mathrm{Y}}=0,832-0,0015 \mathrm{P}^{*}$ & 78,0 & 7,8 \\
\hline
\end{tabular}

$\mathrm{P}=$ Nível de palma na ração (Level of forage cactus).

* Significativo $(\mathrm{P}<0,05)$ pelo teste $\mathrm{t}\left({ }^{*}\right.$ Significant at $(P<.05)$, by $t$ test $)$.

alegando que parte desse problema seja proveniente da grande porcentagem de água existente na palma (Viana, 1965; Santana et al., 1972; Matter, 1986). Todavia, para os níveis de palma utilizados neste experimento, não foi constatado problema dessa natureza, e as fórmulas propostas pelo NRC (1989) e Lucci (1997) para o cálculo da ingestão diária de água por vacas em lactação demonstram que o consumo de água dos animais deste experimento, proveniente da ração, foi inferior ao recomendado, que são de 92,93 e 74 litros, respectivamente.

Apesar de não ter sido avaliado estatisticamente, foi constatado no presente experimento que não houve perda de peso das vacas em nenhum dos tratamentos. Por outro lado, observou-se ganho médio diário nos níveis $0 ; 12 ; 24$ e 36\% de inclusão de palma de 0,311 ; 0,$160 ; 0,377$; e $0,321 \mathrm{~kg}$, respectivamente, que, em parte, pode ter sido em função do excesso de nutrientes verificado nas rações fornecidas.

Os resultados do presente trabalho corroboram as afirmações de Oliveira (1996), recomendando a associação da palma com alimentos ricos em fibra para estimulação da produção de saliva e manutenção das condições normais de rúmen (Sudweeks et al., 1981; Mertens, 1997; Armentano \& Pereira, 1997).

Portanto, sendo a palma uma forrageira que representa um grande potencial para a região semiárida e, em alguns períodos do ano, ser a única fonte de alimento para os ruminantes, sugere-se que estudos mais aprofundados sejam realizados no sentido de determinar mais amplamente sua composição químico-bromatológica e sua associação adequada com fontes de alimentos ricos em fibra, a fim de que se possa fazer melhor uso dessa forrageira.

\section{Conclusões}

Foi possível obter boas produções de leite, manter a gordura do leite em níveis normais e melhorar a conversão alimentar e consumo adequado de nutrientes, para as condições de Agreste Pernambucano, associando-se palma com silagem de sorgo forrageiro.

\section{Literatura Citada}

ALLEN, M.S. Relationship between fermentation acid production in the rumen and requirement for physically effective fiber. In: Symposium: meeting the fiber requirements of dairy cows. Journal of Dairy Science, v.80, n.7, p.1447-1462, 1997.

ALLEN, D.M.; GRANT, R.J. Interactions between forage and wet corn gluten feed as sources of fiber in diets for lactating dairy cows. Journal of Dairy Science, v.83, n.2, p.322-331, 2000.

ARMENTANO, L.; PEREIRA, M. Measuring the effectiveness of fiber by animal response trials. Symposium: Meeting the fiber requirements of dairy cows. Journal of Dairy Science, v.80, n.7, p.1426-1425, 1997.

ASSIS, A.J.; CAMPOS, J.M.S.; VALADARES FILHO, S.C. et al. Polpa de citrus em dietas de vacas em lactação. 1. Produção e composição do leite. In: REUNIÃO ANUAL DA SOCIEDADE BRASILEIRA DE ZOOTECNIA, 37., 2000, Viçosa. Anais... Viçosa: Sociedade Brasileira de Zootecnia, 2000.p.472.

BEHMER, M.L.A. Laticínios, leite, manteiga, queijo, caseína e instalações. 3.ed. São Paulo: Melhoramentos, 1965. 294p.

BEZERRA NETO, E.; ANDRADE, A.G.; BARRETO, L.P. Análise química de tecidos e produtos vegetais. Recife: Universidade Federal Rural de Pernambuco, 1994. 97p.

DAMASCENO, J.C.; BACCARI Jr., F.; TARGA, L.A. Respostas fisiológicas e produtivas de vacas holandesas com acesso à sombra constante ou limitada. Revista Brasileira de Zootecnia, v.27, n.3, p.595-602, 1998.

DIAS, A.M.A. Efeito do estádio vegetativo do sorgo (Sorghum bicolor, (L) Moench), sobre a qualidade da silagem, em comparação à silagem de milho (Zea mays $(L))$ para vacas em lactação. Recife, PE: Universidade Federal Rural de Pernambuco, 1999. 36p. Dissertação (Mestrado em Zootecnia) Universidade Federal Rural de Pernambuco, 1999.

FARIAS I.; FERNANDES, A.P.M.; LIMA, M.A. Cultivo da 
palma forrageira em Pernambuco. Recife: IPA, 1984. 5p. (Documentos, 21).

GRANT, R..J.; COLENBRANDER, V.F.; MERTENS, D.R. Milk fat depression in dairy cows: role of particle size of alfalfa hay. Journal of Dairy Science, v.73, n.7, p.1823-1833, 1990.

GRANT, R.J. Interactions among forages and noforage fiber source. Journal of Dairy Science, v.80, n.7, p.1438-1446, 1997.

HALL, M.B.; LEWIS, B.A.; Van SOEST, P.J. et al. A simple method for estimation of neutral detergent-solubre fiber. Journal of Dairy Science, v.74, n.4, p.441-449. 1997.

LIMA, M.A.; FRANÇA, M.P.; DIAS, F.M. et al. Emprego da associação da palma forrageira e silagem de sorgo na alimentação de vacas holandesas em lactação. In: REUNIÃO ANUAL DA SOCIEDADE BRASILEIRA DE ZOOTECNIA, 22., 1985, Balneário Camboriú. Anais... Balneário Camburiú: Sociedade Brasileira de Zootecnia, 1985. p.133.

SUÁREZ LONDOÑO, A.A.; VALADARES FILHO, S.C.; COELHO DA SILVA, J.F. et al. Somatotropina bovina para vacas de leite em lactação. 1. Produção e composição do leite. Revista Brasileira de Zootecnia, v.26, n.6, p.1227-1233, 1997.

LUCCI, C.S. 1997. Nutrição e manejo de bovinos leiteiros. São Paulo: Manole Ltda., 1997. 169p.

MATTER, H.E. The utilization of Opuntia of livestock. Animal Research and Development, v.23, n.1, p.107-115, 1986.

MATTOS, L.M.E. Associação da palma forrageira (Opuntia fícus indica Mill) com diferentes fontes de fibra na alimentação de vacas mestiças em lactação. Recife, $P E$ : Universidade Federal Rural de Pernambuco, 2000. 51p. Dissertação (Mestrado em Zootecnia) - Universidade Federal Rural de Pernambuco, 2000.

MERTENS, D.R. Análise da fibra e sua utilização na avaliação de alimentos e formulações de rações. In: SIMPÓSIO INTERNACIONAL DE RUMINANTES, 1992, Lavras. Anais... Lavras: Sociedade Brasileira de Zootecnia, 1992. p.188-211.

MERTENS, D.R. Creating a system for meeting the fiber requirements of dairy cows. Journal of Dairy Science, v.80, n.7, p.1463-1481, 1997.

NATIONAL RESEARCHCOUNCIL-NRC. Nutrient requirements of the dairy cattle. 6.ed. Washington, D.C., 1989. 158p.

OLIVEIRA, F.R. Alternativas de alimentação para a pecuária no semi-árido nordestino. In: SIMPÓSIO NORDESTINO DE ALIMENTAÇÃO DE RUMINANTES, 6., 1996, Natal. Anais... Natal: SNPA, 1996, p.127-147.

PIMENTEL, J.J.O.; COELHO DA SILVA, J.F.; VALADARES FILHO, S.C. et al. Efeito da suplementação protéica no valor nutritivo de silagens de milho e sorgo. Revista Brasileira de Zootecnia, v.27, n.5, p.1042-1049, 1998.

PIRES, M.F.A.; TEODORO, R.L.; CAMPOS, A.T. Efeito do estresse térmico sobre a produção de bovinos. In: CONGRESSO NORDESTINO DE PRODUÇÃO ANIMAL, 2., SIMPÓSIO NORDESTINO DE ALIMENTAÇÃO DE RUMINANTES, 8., 2000, Teresina. Anais... Teresina: SNPA, 2000. p.87-105.

RUIZ, T.M.; BERNAL, E.; STAPLES, C.R. Effect of dietary neutral detergent fiber concentration and forage source on performance of lactating cows. Journal of Dairy Science, v.78, n.2, p.305-319, 1995.

SAMPAIO, I.B.M. Estatística aplicada à experimentação animal. Belo Horizonte: Fundação de Ensino e Pesquisa em Medicina Veterinária e Zootecnia, 1998. 221p.

SANTANA, O.P.; ESTIMA, A.L., FARIAS, I. Palma versus silagem na alimentação de vacas leiteiras. Revista Brasileira de Zootecnia, v.1, n.1, p.31-40, 1972

SANTOS, D.C.; MARTINS, E.S.; FARIAS, I. et al. Desempenho de vacas $5 / 8$ holando/zebu alimentadas com três cultivares de palma forrageira (Opuntia e Nopalea). In: SIMPÓSIO NOR-
DESTINO DE ALIMENTAÇÃO DE RUMINANTES, 4., 1992, Recife. Anais... Recife: SNAR/UFRPE, 1992. p.226.

SANTOS, D.C.; FARIAS, I.; LIRA, M.A. et al. A palma forrageira (Opuntia ficus indica Mill e Nopalea cochenillifera, Salm Dyck) em Pernambuco: cultivo e utilização. Recife: IPA, 1997. 23p. (IPA. Documentos, 25).

SANTOS, M.V.F. Composição química, armazenamento e avaliação da palma forrageira (Opuntia ficus indica Mill $e$ Nopalea cochenillifera Salm Dick) na produção de leite em Pernambuco. Recife: Universidade Federal Rural de Pernambuco, 1989. 124p. Dissertação (Mestrado em Zootecnia) - Universidade Federal Rural de Pernambuco, 1989.

SANTOS, M.V.F.; LIRA, M.A.; FARIAS, I. et al. Estudo comparativo das cultivares de palma forrageira gigante, redonda (Opuntia ficus indica Mill) e miúda (Nopalea cochenillifera Salm-Dyck) na produção de leite. Revista Brasileira de Zootecnia, v.19, n.6, p.504-511, 1990.

SANTOS, M.V.F.; FARIAS, I.; LIRA, M.A. et al. Colheita da palma forrageira (Opuntia ficus indica Mill) cv. gigante sobre o desempenho de vacas em lactação. Revista Brasileira de Zootecnia, v.27, n.1, p.33-39, 1998.

SILVA, D.J. Análise de alimentos (Métodos químicos e biológicos). Viçosa: Universidade Federal de Viçosa, 1990. 165p.

SILVA, M.F.; BATISTA, A.M.V.; ALMEIDA, O.C. Efeito da adição de capim elefante a dietas a base de palma forrageira sobre a fermentação ruminal em bovinos. In: REUNIÃO ANUAL DA SOCIEDADE BRASILEIRA DE ZOOTECNIA, 34., 1997, Juiz de Fora. Anais... Juiz de Fora: SBZ, 1997. p.140-142.

SLATER, A.L.; EASTRIDGE, M.L.; FIRKINS, J.L. et al. Effects of starch source and level of forage neutral detergent fiber on performance by dairy cows. Journal of Dairy Science, v.83, n.2, p.313-321, 2000.

SNIFFEN, C.J.; O'CONNOR, J.D.; VAN SOEST, P.J. et al. A net carbohydrate and protein system for evaluating cattle diets: II. Carbohydrate and protein availability. Journal of Animal Science, v.70, p.3562-3577, 1992.

SUDWEEKS, E.M.; ELY, L.O.; MERTENS, D.R. et al. Assessing minimum amounts and form of roughages in ruminant diets: roughages value index system. Journal of Animal Science, v.53, n.5, p.1406-1411, 1981.

UNIVERSIDADE FEDERAL DE VIÇOSA - UFV. SAEG Sistemas de Análises Estatísticas e Genéticas. Versão 7.1. Viçosa, MG, 1997. 150p. (Manual do usuário).

VALADARES FILHO, S.C.; BRODERICK, G.A.; VALADARES, R.F.D. et al. Effect of replacing alfalfa silage with high moisture corn on nutrient utilization and milk production. Journal of Dairy Science, v.83, n.1, p.106-114, 2000.

VAN SOEST, P.J.; ROBERTSONJ, B.; LEWIS, B. A. 1991. Methods for dietary fiber, neutral detergent fiber, and nonstarch polysaccharides in relation to animal nutrition. Journal of Dairy Science, v.74, n.10, p.3583-3597.

VARGA, G.A.; DANN, H.M.; ISHLER, V.A. The use of fiber concentrations for ration formulation. Journal of Dairy Science, v.81, n.11, p.3063-3074, 1998.

VIANA, S.P. O emprego da palma na alimentação de bovinos. In: CONGRESSO INTERNACIONAL DEPASTAGENS, 9., 1965, São Paulo. Anais... São Paulo: DPA, 1965. v.2, p.1461-1464.

WANGSNESS, P.J.; MULLER, L.D. Maximum forage for dairy cows: review. Journal of Dairy Science, v.64, n.1, p.1-13, 1981.

WOODFORD, J.A.; JORGENSEN, N.A.; BARRINGTON, G.P. Impact of dietary fiber and physical form on performance of lactating dairy cows. Journal of Dairy Science, v.69, n.4, p.1035-1047, 1986.

Recebido em: 04/05/01 Aceito em: 08/11/01 